\title{
Science and the stakes of authority
}

\author{
Francisc Gafton* \\ Faculty of Letters, "Alexandru Ioan Cuza" University, Bd. Carol I 11, 700506 Iaşi, Romania
}

"The suppression of intellectual freedom rings the death knell of science"

(Fr. Boas)

\section{Element, system, structure and functions}

By closely observing reality, on the level of either the primary natural products (living organisms) or the derivatives thereof (society, reasoning), we notice that nothing exists without antecedent and devoid of certain connection with the environment. Then, we may understand that, regardless of their rank, the elements collaboratively correlate with each other, differ from one another and hierarchize among themselves forming structurally and functionally unitary systems that are able to co-evolve on ontogenetic and phylogenetic levels. The functioning of the elements within the system, in its turn, has to meet both the requirements of interacting with the environment and the functional-organizational needs of the system itself.

One of the functions thus resulted is that of authority. Not being absolute or centralized or specific to all and any kinds of elements, it tends to take as its locus the elements that have the ability to organize and improve the existential and relational actions of the system in the direction required by its development integrated into the environment. Just like any other systemic function, it does not appear on an individual or singular level (that of the non-integrated element), therefore it is not meant to function on its own, as its coagulating power is neither real nor complete unless it meets the goals which its natural genesis has oriented it towards.

The amazing gene, for instance, exists only inasmuch as it both differs from other genes and takes part in the whole. It exists since it generates, constructs, and operates efficient organisms which thus it serves. This process is fulfilled only through its relations with the fellow parts of the constellation it belongs to, its existential meaning being superior to its mere existence on its own (otherwise impossible) — fact also valid for the system regarded as an element of the environment it belongs to.

On the other hand, though aware of their actions and able to notice causality (as Hume shows it), human beings tend to linger, fascinated, on things and processes in themselves, believing they can covet things and processes per se, just for the sake of their possession and exercise.

Since indeed the system functions only in its entirety, the loss of authority bears the risk of dissolution. A kind of aberrant case-characteristic for organisms unable to ensure the necessary adjustments to the dynamics of reality_appears when, as a result of confusion, different roles are incoherently and abusively assumed, followed by the atomization of authority. For instance, this is what happens when the individual mistakes his/her freedom of speech for the obligation to speak and for guaranteeing the weight of his/her opinion, perhaps in conjunction with the non-obligation to take into account the opinions of his/her peers who are competent in the field.

\footnotetext{
*Email address: algafton@gmail.com.
} 
More than in matters directly affecting the life of individuals and communities, in science-where the equation is the same, what differs is the semblance of terms-, the weight and consequences of the opinion are proportional not to the expressiveness of the locutor, to his/her stakes, hopes, and mental projections or to those of the audience, but exclusively to what extent the conceptual content of the opinion reflects the state or dynamics of reality. Although the ability to find the truth depends on the limits of humans' spatial-temporal and social knowledge, when it reveals itself, it does so by following the path of processes which start from the senses, reach the intellect, and bring reasoning into the order of the Universe; it is not created by imagination, nor is it modulated by ideology.

\section{Action in the fields of knowledge}

As a continuous result of evolutive and adaptive diversification, reality derives from principles that generate differentiated laws which concretize the matter in specific and particular structural and functional ways. Sciences, in their turn, by means of which human mind seeks to acquire knowledge, are bound to comply with reality orienting their methods of observation, examination, and conceptualization according to their abilities to gain access to the foundations and development of reality-criterion by which they are ordered.

Science is in constant need of data, method, and instruments. The data has to comply with the researched reality; the methods have to be appropriate for reality and the field, while the instruments have to be adjusted to the object and method. The need is constant since the research results accumulate over time and spread over space, but both of them are selective and collaborative: the certainties of a century and space may be amended or refuted by the observations, research, and reflections of another century or space, the perspectives being refined, amplified, deepened, evolving. Therefore, the subject matter, methods, and instruments of science are also adjusted, while the domains of rules are specified-often by altering the previous ones, since exercising the rules does not ignore the dynamics of reality or the adjustments of the reasoning to it. Since the reasoning and behavioural adjustments are consistent with the understanding of reality, from time to time everything must necessarily be subjected to verification. Everything is verified, though not everything is eliminated or changed.

The main domains of human science and knowledge, the ones which, in a way or another, include, generate, and provide the premises for all the other kinds of knowledge, are those of physics, chemistry, and biology. Philosophy is a way of reflection and knowledge that employs systems of principles and categories seeking to reach a general conception of the world; logic is a complex of methods, while mathematics is an instrument. Sociology, psychology, and the humanities take over a part of the matter and methods of natural sciences to which they add observations on their own objects, but they fatally separate the matter from the functions and often the functions from the effects of their work, thus eliminating the objective component of reality, making an object out of what remains and, on this basis, dealing with interpretation having the impression that they entirely see their object and that they possess accurate methods and instruments-in fact, partially borrowed from natural sciences, partially crafted by themselves.

Generally, the fundamental sciences are not dominated by autonomy complex; the nature of the researched reality helps to understand its organic and inextricable character, while the potential distinctions operated within it serve only methodological purposes. On the grounds of a seemingly privileged past, the domains of abstract thinking have always encountered difficulties in keeping pace with natural sciences, since they are reluctant and insecure when it comes to dismiss speculative reasoning and the construction of such systems or to abandon embedding, for processing purposes, the data provided by science, despite all the empirical evidence. The domains of interpretation, in their turn, constantly claim their autonomy and they ceaselessly try to demonstrate it, though within certain endeavours which indicate exactly the opposite. Furthermore, since the authority is restricted and censored by empirical and inductive supremacy, reaching its maximum where interpretation prevails-the plurality of perspectives being but a sign of shortcomings within the knowledge and understanding of reality which is infinitely more uniform 
than thinking imagines and wants it to be-, in the domains of interpretation, where meaning is sought at all costs, since the empirical basis is missing, it ends up being induced, the maximal self-referentiality manifesting itself by the searching for its own purposes and stakes, the result induced by speculative means from the (abstract, ethic, conceptual, etc.) meanings, in conjunction with the tautological recourse to the "truth" issued by authority.

\subsection{The stakes}

The stakes constitute such a peculiar aspect that they may serve to teach us moderation and equilibrium. Subsequent to embracing and understanding reality, they may become projections that harmonize the reasonable desiderata of human beings with the dynamics of the world. Discarding their status of tools and becoming essential elements, the stakes disconnect from reality arrogating their ability to build the future while changing reality towards the stakes and meanings invented by men-always against the grain of objective reality. This misjudgement has the strange structural beauty and functional ingenuity of a virus since ignoring the status of a part within the system and assuming to be an architect of an unknown world, by means of stakes, men: a) overstate their actual position, abilities, and potential; b) take advantage of the functioning of the system only to live on it as a parasite.

In biology there are two main theories regarding the emergence of living matter. Abiogenesis claims that organic and living matter derives from inorganic and non-living substances by means of a spontaneous generation. Attentive to the consequences drawn from here rather than to the essence of the whole conception, the $18^{\text {th }}-19^{\text {th }}$ centuries' thinking considered that abiogenesis implies the existence of deity, therefore scientific endeavours were oriented towards demonstrating how groundless this theory was and banishing the Divine from the world, by virtue of adopting a scientific conception (which sometimes may act as belief does). In his time, Pasteur proves the principle summarized in the phrase omne vivum ex vivo and he gives arguments for biogenesis, seemingly abolishing the theory of spontaneous generation. Nevertheless, God has the power to appear at any time and He always sits at the beginning of all things. As a matter of fact, biogenesis is the one that is in imperative need of God since abiogenesis may do without deity just like Laplace's cosmological system. Only after the partial release from the obsession of this stake, by recalling that science seeks to discover reality as it is, scientists could let scientific evidence and arguments to show and teach them what reality might truly be.

Also in biology, the so-called central dogma states that information cannot be transferred from protein to protein neither can it be transferred back from protein to nucleic acid, i.e. DNA makes RNA and RNA makes protein and the interaction between protein and the environment does not affect the DNA. Human genome mapping, however, has showed too many normal cases that contradict the dogma. Nonetheless, the supporters of the so-called modern evolutionary synthesis put a lot of rhetorical and linguistic effort into interpreting or minimalizing this evidence because, by doing so, they could keep denying the inheritance of acquired characteristics' principle (stated by Lamarck, accepted and employed by Darwin, practically unsurpassed by empirical and inductive evidence of science, denied only on the basis of interpretation, on ideologicalconceptual grounds and criteria).

The outcome of the first situation shows that, with no fear, the stakes resume their role of reasonable purposes of the society and the individuals, guided by rational impulses, accommodated and adjusting to the well-balanced course of evolution. In this way, humans become able to reflect not upon how they could demolish and rebuild reality in their own image and according to their ambitions but upon how they could better adapt to the reality they belong to, becoming a contributing part of it (this would be the second house of Descartes).

The second situation shows that the accumulations of mankind are not irreversible or nonperishable, the primary brain dominating the neocortex. Perhaps the solution consistent with 
reality shall be given by the future generations-free from this kind of fear, enslaved to others-, since in viable homeostatic systems the natural way of being is the truth.

\subsection{The dogmas}

By dramatically twisting the search for the truth and its results, the stakes bring about the construction and establishing of dogmas. Deriving from what human - anthropocentric and hermeneutic-beings want to see at all costs, the dogmas are signs of struggle and they result from the lack of knowledge and understanding of reality, from non-understanding the immanent nature of authority and control distributivity within a system, leading to abide by certain stakes that are aberrant with respect to reality. They not only imply the persecution of Christians by lions and then that of the pagans by Christians, but they also prolong the aberrant fight of Weismann and Mayr with Neo-Lamarckism and Darwinism, deviating from the natural course of civilisation and producing warmth rather than light. However, the rational embracement of a theory and the acceptance of its validity does not generate the natural behavioural changes either; the previous belief and stakes may be overwhelming, since the dogma makes it easier to believe the conjectures of mind than the reflections of reason by offering the seeming comfort of a false certainty, whereas science threatens with an incomplete or lacking answer or with the extremely inconvenient answer. This is why Tycho Brahe imagines a planetary system of compromise between the Copernican and Ptolemaic systems-with planets revolving around the Sun, but with Earth in the centre-; this is why people prefer belief to research or they do research on paths that would lead them to the answers they believe to be in need of; this is why it takes centuries for men to accept the truths of reason that have been proven by the facts of reality but it takes only a few seconds to believe the figments and absurdities of mind upheld - like El Cid on horseback on his last day of glory — by the charming and memorable, yet insufficiently or defectively devised formula.

\section{Equilibrium}

While examining the features of the constitutive elements of the system and its functional structure, it may be noticed that the bases of efficient being are the fundamental principles that govern the establishment, functioning, interaction, and evolution, on collaborative-competitive grounds, of all kinds of elements and systems. The system cannot exist if it contradicts the principles which it is based on, neither can the elements exist if they contradict the norms of the system they belong to. When that seems to be the case, the evolutionary tendencies of the system are accomplished. When that is the case, the integrity of the system is put at risk.

Scientific knowledge-a product of evolution-, in its turn, is a long-lasting and difficult process meant to lead reason to the just understanding of reality (especially since it is counter-intuitive, as reason says other than senses do, and it is negative, as it certifies what does not exist, merely suggesting what there could be). Since the ways of reality do not correspond to the labyrinths created by human mind, intuition and preconceptions, observation and experience, the stakes and vanity must consistently be submitted to rationality. Since human mind is subject to confusions and it may conceive stakes and dogmas-i.e. elements bearing the illusion of guides that restrain from deviations and bring about progress, while they only ensure self-preservation preventing the adaptive evolution of the organism -, it must free itself from such responsibilities in order to steadfastly search for the truth.

According to those stated above, it is reasonable to admit that knowledge ought to be acquired by the learned, while behavioural skills should be provided by the experienced. Emerging where the conjunction between objective observation and unfettered reflection has led to the understanding of the foundations and processuality, consolidating science and experience by discernment and goodwill, authority is the result of a delicate and demanding process, since both the ultimate stability and the continuous instability are destructive, as equilibrium is provided by the well-balanced relation between finding the stability that 
ensures identity and longevity and seeking variability which generates adjustment to reality and evolvement. These features - scarcely found in individuals and lacking in success within groups, as Helvetius states-generate not only the understanding of things and processes but also the responsible assuming of a role consistent with the abilities of the part to work in the best interest of the whole. The path to be followed is the one that makes the internalization of norms to lead towards rational understanding and rationalized behaviour rather than towards beliefs and stakes.

Any stage, however well founded, remains incomplete, perishable, and ephemeral, as the purpose of its coming into being is not its immortalization but to serve the edifice it contributes to and which incorporates it, just like the child vanishes once becoming a teenager who later on, being accomplished, turns into a young man selectively consumed by the adult, the life of the part being but a moment in the existence of the whole. 